\title{
DESENVOLVIMENTO INTERATIVO DE UM ROBÔ PARA EXECUÇÃO DE ATAQUES DE ENGENHARIA SOCIAL NO TWITTER
}

\author{
Jefferson Viana Fonseca Abreu, Jorge Henrique Cabral Fernandes e João José Costa Gondim \\ Departamento de Ciência da Computação - Universidade de Brasília (UnB) \\ Campus Universitário Darcy Ribeiro, UnB - Brasília, DF, 70910-900, Brasil
}

\begin{abstract}
RESUMO
Uma série de robôs que realizam ataques simulados de engenharia social do tipo phishing, na plataforma twitter foi desenvolvida iterativamente. Três diferentes experimentos coletando dados para a identificação de atributos das contas que indicassem quais delas seriam mais vulneráveis a esse tipo de ataque, visando o futuro desenvolvimento de estratégias para sensibilização de usuários foram executados. Embora os resultados sobre os preditores de comportamento de usuários ainda sejam inconclusivos, os demais resultados obtidos indicam ser possível a execução continuada de ataques de phishing no twitter, apesar das estritas políticas de segurança adotadas na plataforma.
\end{abstract}

\section{PALAVRAS-CHAVE}

Robôs, Phishing, Twitter, Cibersegurança

\section{INTRODUÇÃO}

O phishing é uma técnica de engenharia social que pode ser definida como uma fraude escalável onde a personificação e usada como forma de ganhar influência e (ou) persuasão, visando coletar informações da vítima, que não seriam normalmente fornecidas. [Lastdrager 2014] Podemos assim, dividir o ataque de phishing em duas etapas: (i) personificação e (ii) coleta de informações. E usual o emprego de robôs que realizam ataques de phishing de maneira automatizada, o que agrava substancialmente a situação. Esses tipos de ataques representam uma séria ameaça a segurança da informação, pois aumentam o alcance dos golpes, [Lauinger et al. 2010] tornando-os mais baratos. [Huber et al. 2009].

Hoje em dia a inteligência artificial é avançada o suficiente para produzir robôs que são capazes de se passar por seres humanos, [Shafahi et al. 2016] este tipo de robô é chamado de robô social. Segundo [Rouse 2013] um robô social é um software que é capaz de simular o comportamento humano através de interações automatizadas em uma rede social online. Robôs podem ser utilizados em redes sociais com motivações boas (por exemplo um chatbot que interage com clientes de alguma organização), mas também podem ser utilizados para tarefas malevolentes como compartilhar spam, vetores para phishing ou disseminação de fake news. [Freitas et al. 2015].

\subsection{Trabalhos Relacionados}

Em [Lauinger et al. 2010] são descritos ataques que simulam o comportamento humano, performados no $I R C$. Por sua vez [Jakobsson e Ratkiewicz 2006] estuda ataques onde o alvo e um sítio de leilões online além de promover uma discussão sobre a ética envolvida em realizar este tipo de pesquisa científica. $\mathrm{O}$ artigo [Shafahi et al. 2016] relata o uso de robôs que simulam o comportamento humano para testes sobre phishing no twitter e é o que mais se assemelha a este trabalho pois nele os testes também usam a plataforma twitter.

Uma das ameaças aos usuários do twitter é o phishing [Shafahi et al. 2016], sendo um problema já conhecido a dificuldade de detectar este tipo de investida. [Purkait 2012, Jakobsson et al. 2008, Hatfield 2018]. Entretanto, alguns estudos já demonstraram que os trabalhos que objetivam educar as pessoas contra essa ameaça apresentam bons resultados. [Alencar et al. 2013, Purkait 2012]. Assim sendo, o pressuposto deste trabalho foi de que, para se obter resultados mais impactantes contra o phishing, é necessário conhecer mais sobre essa forma de ataque. 


\subsection{Declaração de Contribuição}

A principal contribuição do trabalho é a engenharia reversa da detecção de robôs do twitter. Além disto também houve a descrição do processo de concepção (e arquitetura) de um robô que simula ataques de engenharia social automatizada no twitter, e que possui grande chance de atuar de forma continuada, sugerindo que a mídia social twitter ainda não está plenamente preparada para mitigar o abuso da plataforma por robôs.

\section{DESCRIÇÃO DO PROBLEMA}

O problema em questão é a identificação de atributos das contas que indicassem quais delas seriam mais vulneráveis a um ataque de phishing no twitter, visando o futuro desenvolvimento de estratégias para sensibilização de usuários foram realizados. Para a identificação destes dados, foram desenvolvidos robôs para coleta de informações.

\section{METODOLOGIA}

A pesquisa buscou ser elaborada dentro de estritos critérios científicos e éticos, observada a dificuldade o fenômeno a ser investigado, vislumbrando testar conceitos sobre a operação do phishing. Os ataques executados foram feitos da maneira mais inócua possível, sem coleta de dados eventualmente informados pelos usuários atacados. Neste experimento os participantes não foram explicitamente avisados que estavam em um experimento científico vislumbrando evitar que esses apresentassem comportamento divergente ao que ocorreria em seu cotidiano. Apesar disso, os participantes foram informados implicitamente sobre o experimento, como é explicado na seção 4.1. A sequência de experimentos foi executada com graus de complexidade incrementais, onde os dados e resultados obtidos em um experimento de sequência $x$ indicavam os caminhos seguintes com funcionalidades a serem inseridas no experimento de sequência $x+1$.

\subsection{Planejamento dos Ataques}

O planejamento dos ataques consistiu em definir o que seria executado para cumprir o objetivo do experimento, com base em seis etapas: (1) Identificação do fluxo de tuítes As contas a serem atacadas seriam escolhidas a partir da atividade de publicação de tuítes, obtido através do uso de palavras-chave, para escolher as possíveis vítimas, conforme seus grupos de interesse; (2) Obtenção do fluxo de tuítes Seria obtido no twitter um fluxo contínuo de tuítes associados aos grupos de interesse, os quais seriam armazenados em um buffer assincronamente consumido; (3) Amostragem de contas À medida que o fluxo de tuítes fosse consumido, deveria realizar-se uma amostragem das contas, identificando aquelas que seriam atacadas; (4) Personificação, por meio do envio de estímulos para as contas a serem atacadas, deveriam ser enviados estímulos, oferecendo informações de potencial interesse aos usuários dessas contas; (5) Análise da resposta os estímulos Para os usuários que "morderam a isca" a partir dos tuítes, lhes seria apresentada uma página que supostamente buscava completar o ataque, por meio da coleta de dados pessoais; e (6) Contabilização Os dados que relatam o comportamento do usuário (tempo de visita à página após o ataque, oferta de dados pessoais, visita à página do sítio etc) seriam contabilizados.

\section{TESTES E RESULTADOS}

Cada experimento demandou conhecer com mais profundidade como o twitter funciona, e quais estratégias seriam suficientes para viabilizar o funcionamento dos robôs. Os tópicos mais comentados se distribuíam entre eventos musicais, reality shows, grandes eventos esportivos e investigações da Polícia Federal [Alves 2017]. Depreendeu-se que os assuntos mais comentados pertenciam a 3 grandes áreas: Entretenimento, esportes e política. Essas foram as áreas temáticas escolhidas para os demais experimentos. 


\subsection{Robô/Experimento 1}

$\mathrm{O}$ primeiro experimento testou a primeira estratégia de ataques de phishing. $\mathrm{O}$ servidor web, desenvolvido nesse experimento, foi o mesmo utilizado em todos os subsequentes. Esse apresentava uma página contendo um formulário que solicitava dados pessoais do usuário, para um suposto cadastro, visando em seguida apresentar-lhe uma notícia. Todos os acessos foram contabilizados. A página apresentava dois botões: "Acessar" e "Acessar sem cadastro", e também uma url, cujo texto era: "Para ver o projeto desta pesquisa científica clique aqui". Essa última url direcionava o usuário a leitura do projeto real da pesquisa aqui relatada. A figura 1 mostra um exemplo da página mostrada as vítimas.

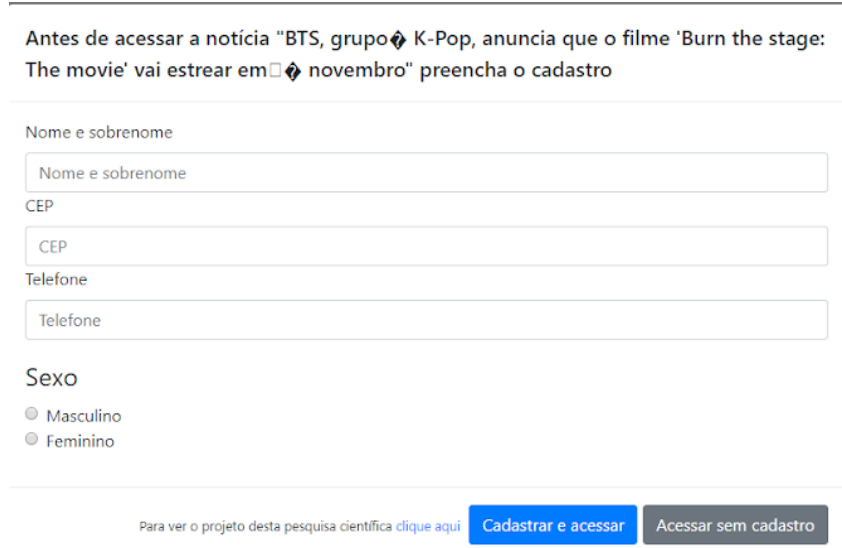

Figura 1. Exemplo da página mostrada aos usuários que respondiam ao ataque

O experimento 1 foi executado em duas baterias, sendo uma curta, de 30 minutos, no décimo oitavo dia da pesquisa, e outra longa, com duração de 3 horas, no décimo nono dia da pesquisa, quando então ocorreu o banimento das contas que estavam sendo usadas pelo robô, pela plataforma twitter. A duração dos ataques foi de apenas algumas horas. Utilizaram-se 2 contas diferentes, onde cada conta realizava postagens específicas em uma das áreas temáticas: esportes ou entretenimento. Foram enviados 65 tuítes (32 em uma conta e 33 em outra) para usuários distintos. Os pesquisadores optaram por não realizar testes com o assunto política, pois o experimento 1 foi realizado durante o período da campanha eleitoral brasileira de 2018.

Apos a realização do experimento 1 foi compreendido que o robô não atendia aos requisitos funcionais estabelecidos. Ele deveria ser bem mais sutil para passar desapercebido pelos mecanismos de detecção do twitter. Isso fomentou um refinamento nos requisitos dos robôs. Através de uma nova leitura das regras de uso da API do twitter perceberam-se que os estavam falhando nos seguintes pontos: (i) todos os tuítes faziam menções as contas atacadas; (ii) muitas postagens eram duplicadas ou muito semelhantes e (iii) o robô realizava o redirecionamento dos usuários para uma página intermediária, antes de enviar para a notícia.

\subsection{Robô/Experimento 2}

O objetivo do Robô/experimento 2 foi solucionar as falhas do experimento anterior. Para cada uma das três falhas do experimento 1 foi adotada uma técnica de mitigação. Para (i), a mitigação consistiu em fazer a postagem de outros tuítes, intercalados com os tuítes de pseudo-ataques. O ponto (ii) motivou a diversificação das iscas enviadas, combinada com postagem de tuítes que não eram ataques. Já (iii) não havia como ser corrigido, como não foi possível evitar o redirecionamento, usou-se um encurtador de urls.

Os ataques ocorreram durante 2 dias ininterruptos. Os testes foram suspensos devido a mais um bloqueio de uma das contas utilizadas, dentre as 3 contas diferentes usadas por três robôs, cada uma com postagens específicas em uma das áreas temáticas: política, esportes ou entretenimento. Não se sabia ao certo o porque da conta ter sido banida. Foram levantadas três razões possíveis para explicar esse banimento: um alvo fez uma denúncia; o robô agia $24 \mathrm{~h}$ por dia, sem pausa; o robô realizava postagens com muita frequência. 
O experimento 2 não produziu dados de interação de usuários que por si só fossem relevantes. Entretanto, existiram fortes indicativos de que o desenvolvimento dos experimentos estava progredindo de maneira satisfatória. Apesar do banimento de uma das contas, essa conta ficou muito mais tempo executando, se comparado ao experimento 1. A tabela 1 mostra a quantidade de ataques enviados no experimento 2 , segmentados por área temática.

\subsection{Bot/Experimento 3}

De modo semelhante ao ocorrido no experimento 2, os aprendizados obtidos no experimento anterior serviram para embasar as melhorias na nova versão do programa de computador. Foram adotadas técnicas de mitigação para as razões possíveis do banimento da conta perdida no experimento anterior.

Percebeu-se que os experimentos não poderiam ser executados de maneira ininterrupta. Por isso, durante a madrugada, os experimentos passaram a ser interrompidos. Além disso, constatou-se que os robôs deveriam atuar de maneira menos frequente, ficando mais parecidos com o comportamento humano [Almeida e Gondim 2019]. A diminuição da velocidade de postagem de tuítes ocorreu através de uma solução bastante simples: desprezando uma fração significativa dos alvos em potencial.

Após os ajuste, os testes foram retomados, e sua interrupção ocorreu por decisão dos pesquisadores, não tendo ocorrido nenhum problema com a plataforma diferentemente dos experimentos 1 e 2 . Foram utilizadas 2 contas diferentes, onde cada robô controlava uma conta e realizava postagens específicas em uma das áreas temáticas: política ou esportes. Durante toda a execução do experimento 3, foram enviados 569 mensagens com urls, distribuídos entre os assuntos política e esportes. Se comparado com o experimento anterior, foram enviados $17 \mathrm{urls}$ a mais no assunto política, e $56 \mathrm{urls}$ a mais no assunto esportes. A tabela 1 mostra a quantidade de tuítes de ataques enviados no experimento 3 , segmentados por área temática.

Tabela 1. Tuítes de ataques por assunto, nos experimentos 2 e 3

\begin{tabular}{ccccc}
\hline Experimento & Política & Esportes & Entretenimento & TOTAL \\
\hline 2 & 336 & 160 & 245 & $\mathbf{7 4 1}$ \\
\hline 3 & 353 & 216 & - & $\mathbf{5 6 9}$ \\
\hline
\end{tabular}

\section{DISCUSSÃO}

Os robôs aqui criados são menos sofisticados que os descritos em [Shafahi et al. 2016] no que concerne à simulação de comportamento humano. Entretanto as interações com usuários que sinalizam que ao menos alguns os robôs conseguiram se passar por usuários humanos. Além disso, a pesquisa aqui relatada desenvolveu ataques mais agressivos, que entraram em contato direto com as vítimas, por meio de menções às suas contas sem, no entanto, coletar dados que permitissem a posterior identificação da vítima. A pesquisa, embora não tenha identificado quais fatores seriam fortes preditores do comportamento inseguro de usuários, conseguiu produzir resultados significativos. O robô desenvolvido no experimento 3 demonstrou ser estável, realizando ataques por cerca de 10 dias, sem detecção. Somados aos dados do experimento 2, o número de ataques realizados foi acima de mil. A principal contribuição deste artigo foi é a engenharia reversa da detecção de robôs do twitter, pois algumas regras puderam ser inferidas na medida que os robôs foram melhorando ao evadir-se dessas. Além disso outra colaboração é a concepção de uma metodologia exploratória para construir robôs capazes de burlar os mecanismos automáticos de verificação do twitter. Os resultados sugerem que, aparentemente, a detecção de robôs no twitter não envolve meios linguísticos (como detecção de expressões regulares), mas a observação de comportamentos claramente não humanos em parâmetros como frequência e continuidade de tuítes, duração de período de atividade e similares. Essa abordagem de detecção e bem simples e geral, e busca não impactar a experiência do usuário. 


\section{CONCLUSÃO}

Foi proposta e executada uma metodologia iterativa incremental para desenvolvimento de experimentos na construção de robôs que simulam ataques de engenharia social do twitter, tendo sido desenvolvido um robô que conseguiu funcionar, por dez dias sem detecção no twitter, atacando usuários de forma potencialmente agressiva. Os acertos podem vir a ser utilizados em futuros experimentos relacionados ao tema. Os erros cometidos nos experimentos 2 e 3 também podem ser utilizados como exemplos de más práticas, a não serem repetidas. Na perspectiva de trabalhos futuros, espera-se repetir o experimento durante um período maior de tempo, com execução em outras plataformas, e observando outros atributos dos usuários visando mapear preditores mais significativos de comportamento inseguro de usuários diante de ataques de engenharia social.

\section{REFERÊNCIAS}

Alencar, G. D., Lima, M., Firmo, A. C. (2013). O efeito da conscientização de usuários no meio corporativo no combate à engenharia social e phishing. IX simpósio Brasileiro de Sistemas de Informação (SBSI'13), páginas 254-259.

Almeida, P. S. e Gondim, J. J. C. (2019). Click Fraud Detection e Prevention system for Ad Networks. Journal of Information Security e Cryptography (Enigma), 5(1):27-39.

Alves, S. (2017). Twitter revela principais assuntos e tweets na rede social no Brasil e no mundo em 2017. de São paulo, F. F. (2017). Rock in Rio e 'BBB' são os assuntos mais comentados no Twitter.

Freitas, C., Benevenuto, F., Ghosh, S., e Veloso, A. (2015). Reverse engineering socialbot infiltration strategies in twitter. In 2015 IEEE/ACM International conference on Advances in Social Networks Analysis e Mining (ASONAM), páginas 25-32. IEEE.

Hatfield, J. M. (2018). Social engineering in cybersecurity: The evolution of a concept. Computers \& Security, 73:102-113.

Huber, M., Kowalski, S., Nohlberg, M., e Tjoa, S. (2009). Towards automating social engineering using social networking sites. Em Computational Science and Engineering, 2009. CSE'09. International Conference, volume 3, páginas 117-124. IEEE.

Jakobsson, M. e Ratkiewicz, J. (2006). Designing ethical phishing experiments: a study of (rot13) ronl query features. Em Proceedings of the 15th international conference on World Wide Web, páginas 513-522. ACM.

Jakobsson, M., Johnson, N., e Finn, P. (2008). Why and how to perform fraud experiments. IEEE Security \& Privacy, 6(2).

Lastdrager, E. E. (2014). Achieving a consensual definition of phishing based on a systematic review of the literature. Crime Science, 3(1):9.

Lauinger, T., Pankakoski, V., Balzarotti, D., e Kirda, E. (2010). Honeybot, your man in the middle for automated social engineering. In LEET.

Purkait, S. (2012). Phishing counter measures e their effectiveness-literature review. Information Management \& Computer Security, 20(5):382-420.

Rouse, M. (2013). What is socialbot? - Definition from WhatIs.com.

Shafahi, M., Kempers, L., e Afsarmanesh, H. (2016). Phishing through social bots on twitter. Em Big Data (Big Data), 2016 IEEE International Conference, páginas 3703-3712. IEEE. 